Research Article

\title{
Strength and Expansion and Deformation Characteristics of Modified Expansive Soil by Octadecylamine
}

\author{
Jun-Hua Wu $\mathbb{D},{ }^{1,2,3}$ Wei-Chao Ao, ${ }^{1}$ Mao-Sheng Wang, ${ }^{1}$ Jia-Ming Liu, ${ }^{1}$ and Fang-Yuan Fu ${ }^{1}$ \\ ${ }^{1}$ College of Civil Engineering and Architecture, Nanchang Hangkong University, Nanchang, JiangXi, China \\ ${ }^{2}$ Key Laboratory of Hydraulic and Waterway Engineering of the Ministry of Education, Chongqing Jiaotong University, \\ ChongQing, China \\ ${ }^{3}$ Key Laboratory of Failure Mechanism and Safety Control Techniques of Earth-Rock Dam of the Ministry of Water Resources, \\ Nanjing, JiangSu, China
}

Correspondence should be addressed to Jun-Hua Wu; wjh0796@nchu.edu.cn

Received 28 June 2021; Accepted 17 August 2021; Published 30 August 2021

Academic Editor: Guang-Liang Feng

Copyright (C) 2021 Jun-Hua Wu et al. This is an open access article distributed under the Creative Commons Attribution License, which permits unrestricted use, distribution, and reproduction in any medium, provided the original work is properly cited.

Octadecylamine was used as a primary water repellent and mixed into the remodeled expansive soil, and modified expansive soils with different water contents and octadecylamine contents were configured. The water repellency level of the modified expansive soil was determined by the drip penetration time method, the corresponding free, unloaded, and loaded swelling rate tests were carried out, and the law of the influence of octadecylamine content and water content on the expansion and deformation of expansive soil was obtained. It can be shown that the modified expansive soil with an octadecylamine content of $0.8 \%$ (mass fraction) had an extreme water repellent grade, and the water repellency remained stable. The more the water content and octadecylamine content, the lower the free swelling rate, and the unloaded swelling rate and loaded swelling rate of modified expansive soil tended to be stable. When the octadecylamine content was $0.5 \%$ and $0.8 \%$, the free expansion rate was significantly reduced, and the maximum drop was $42 \%$. When the octadecylamine content was increased from $0 \%$ to $0.8 \%$, the uncharged expansion stability duration was shortened from $97 \mathrm{~h}$ to $47 \mathrm{~h}$, and the expansion rate was reduced from $12.9 \%$ to $9.4 \%$. When the mass fraction of octadecylamine was $0.8 \%$, the modified expansive soil with a water content of $20 \%$ would decrease its load expansion rate from $2.14 \%$ at $50 \mathrm{kPa}$ to $0.01 \%$ at $400 \mathrm{kPa}$. When the load was small, the octadecylamine content and initial water content had a greater impact on the loaded expansion rate; when the load was large, the load became the main factor affecting the loaded expansion rate. Under the same overburden pressure, the more the octadecylamine content was, the lower the soil shear strength was and the more it tended to be stable.

\section{Introduction}

With the gradual implementation of the strategic goal of "One Belt and One Road" in China, many expansive soil areas will encounter geological and climatic challenges, which may lead to engineering safety problems, such as slope instability, pipe gushing, ground deformation, ground subsidence [1-7]. Expansive soils are rich in hydrophilic clay minerals such as montmorillonite [8], and their engineering properties are more complex than those of general clay soils: effects of water will lead to rapid deterioration of engineering properties of expansive soil, causing long-term serious damage to projects in expansive soil areas, resulting in huge economic losses and human casualties [9]. Therefore, it is of great significance to reasonably solve the engineering problems of expansive soil [10].

There are many research studies on the modification of expansive soil. As early as 1966, Ring [11] studied the problem of soil shrinkage swelling potential and analyzed the basic physical properties of different soils. In 1993, Koyluoglu [12] mentioned that expansive soil had great expansion and contraction property. In addition to its internal structure, the external water mainly entered into it, which provided guidance for the research of expansive soil. In recent years, Gao et al. [13] carried out a series of modification on expansive soil, including physical 
modification [14-16], biological modification [17-19], and chemical modification [20-22], and carried out corresponding tests to evaluate these three modification methods. In 2014, Malekzadeh and Bilsel [23] studied the application and influence of crabapple ash in the stability of expansive soil. In 2018, Moghal et al. [24], in the case of lime stabilization, proposed synthetic fiber as an alternative to solve the problem of shrinkage and expansion in expansive soil. Jahangir khazaei et al. [25] improved soft expansive soil by environmental waste and lime. In 2020, Blayi et al. [26] proposed to use waste glass powder (WGP) to improve expansive soil, and Wang et al. [27] conducted a systematic study on the modification of expansive soil with cement. Meng et al. [28] studied the influence of cementing fluid concentration on mechanical properties, microstructure, and hydrological characteristics of expansive soil. Some scholars [29, 30] have adopted materials such as lime $[31,32]$, cement [33], rubber particles [34], natural sand and gravel [35], rock fiber [36], blast furnace water slag [37], and even vegetation root system [38] to improve the expansion and shrinkage properties of expansive soil. After studying the swelling properties of the expansive soil after chemical modification, it was found that the expansive soil itself still had strong hydrophilicity, and the modification effect is not obvious, but it is realized that waterproofing is of great importance in the protection of expansive soil engineering [39]. The current commonly used waterproofing measures only isolate part of the soil from water, without changing the intrinsic nature of soil hydrophilicity, and the long-term impermeability cannot be guaranteed. Once water enters the soil and acts repeatedly for a long time, the seemingly stable slope may still be unstable again [40].

If expansive soil particles can be treated by technical means to make them change from hydrophilic to hydrophobic and, at the same time, if their expansive deformation characteristics can be improved, then the swelling and shrinkage deformation problems caused by the change of moisture in expansive soil can be effectively avoided, and the corresponding engineering problems can be solved [41]. Therefore, in this paper, octadecylamine was used as the water repellent. By configuring expansive soil samples with different initial water contents and different octadecylamine contents, the water repellency level determination tests and swelling rate tests were carried out, and the influence law of different octadecylamine contents and initial water contents on the water repellency and swelling deformation of modified expansive soil was obtained, which provided new ideas for effectively solving expansive soil engineering problems.

\section{Test Materials and Methods}

2.1. Experiment Materials. The soil for the test was taken from an area of Kunming City, dried and ground, and then passed through a $2 \mathrm{~mm}$ sieve for reserve. Based on the provisions in Highway Geotechnical Test Rules (JTG E402007), the basic parameters were as follows: relative density was $2.71 \mathrm{~g} / \mathrm{cm}^{3}$, maximum dry density was $1.56 \mathrm{~g} / \mathrm{cm}^{3}$, optimal water content was $27.2 \%$, liquid limit was $63.5 \%$, plastic limit was $30.8 \%$, plastic index was 32.7 , and free expansion rate was $52 \%$. The free expansion rate of this expansive soil was less than $60 \%$, and it belonged to weakly expansive soil. The BT-9300Z laser particle size analyzer produced by Dandong Baxter Instrument Co., Ltd., was used to determine the particle size distribution curve, as shown in Figure 1, and the proportions of soil particle mass with particle size $<0.002 \mathrm{~mm}, 0.002-0.02 \mathrm{~mm}$, and $0.02-2 \mathrm{~mm}$ were $6.72 \%, 56.32 \%$, and $36.96 \%$, respectively. According to the International Triangle Classification of Soil Texture, the test soil was silty loam.

\subsection{Experiment Method}

2.2.1. Test of Water Repulsion Grade. The water repellent grade of modified expansive soil was determined by the dripping penetration time method, and the classification standard is shown in Table 1 . After mixing $0 \%, 0.2 \%, 0.3 \%$, $0.5 \%$, and $0.8 \%$ octadecylamine with expansive soil, it was placed in an oven with $75^{\circ} \mathrm{C}$. It was taken out per two hours and put into the oven after mixing. The modified expansive soil was obtained by mixing four times. Octadecylamine is a surfactant with extreme water repellency. Its chemical properties are as follows: melting point $-50-52^{\circ} \mathrm{C}$ and freezing point $-53.1^{\circ} \mathrm{C}$. Therefore, when the temperature is between $75^{\circ} \mathrm{C}$ and $80^{\circ} \mathrm{C}$, octadecylamine can be liquified and then encapsulated outside the soil particles, as shown in Figure 2 (the white matter outside the soil is octadecylamine). In order to reduce the influence of sample preparation nonuniformity, the dripping penetration time was measured at three places (regular triangle distribution and spacing of $4 \mathrm{~cm}$ ) on the sample surface, and the amount of dripping water at each place was $80 \mu \mathrm{L}$. We take the average as the final result. The temperature was controlled at $24^{\circ} \mathrm{C}$ during the whole test $\left( \pm 1^{\circ} \mathrm{C}\right)$, and humidity was controlled at $64 \% \pm 2 \%$.

2.2.2. Free Expansion Rate Experiment. Five kinds of modified expansive soils with octadecylamine content of $0 \%$, $0.2 \%, 0.3 \%, 0.5 \%$, and $0.8 \%$ were selected in the experiment. According to the standard for soil test methods (by GB/ T50123-2019), the free expansion rate tests of five kinds of modified expansive soils with octadecylamine content of $0 \%$, $0.2 \%, 0.3 \%, 0.5 \%$, and $0.8 \%$ were carried out.

2.2.3. Unloaded Expansion Rate Test. According to the test results of water repellent grade, 20 groups of samples with octadecylamine content of $0 \%, 0.2 \%, 0.3 \%, 0.5 \%$, and $0.8 \%$ and initial water content of $5 \%, 10 \%, 15 \%$, and $20 \%$ were selected. After sealing for 24 hours, the jack (Figure 3(a)) was used for sampling. According to the standard for soil test methods (GB/T50123-2019), the unloaded expansion rate test was carried out by using WG-1B triple medium pressure consolidometer (Figure 3(b)).

2.2.4. Loaded Expansion Rate Test. According to the standard for soil test methods (GB/T50123-2019), the loaded expansion test was carried out. According to the test results of 


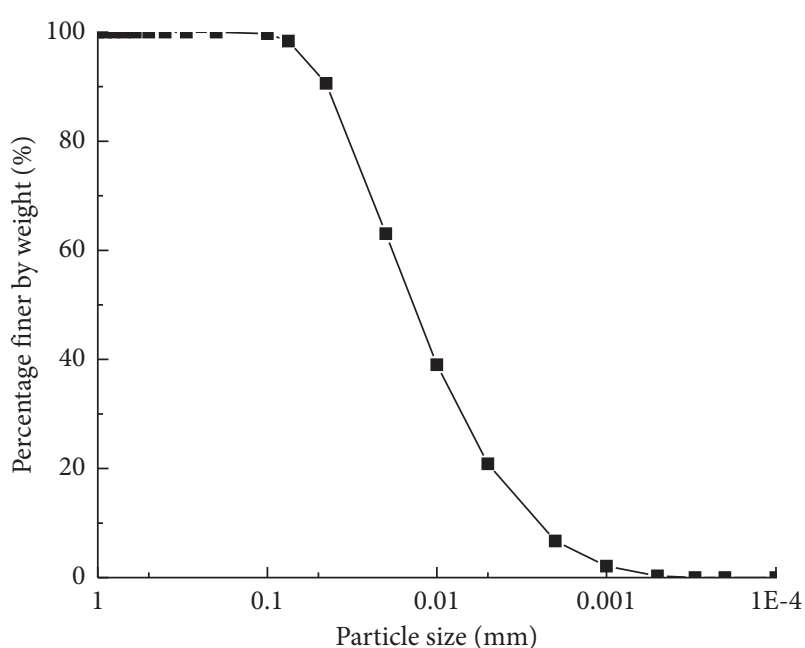

FIgURE 1: Gradation curve of expansive soil particle size.

TABLE 1: Classification standard of WDPT

\begin{tabular}{lccccc}
\hline $\begin{array}{l}\text { Infiltration } \\
\text { time }(\mathrm{s})\end{array}$ & $<5$ & $5 \sim 60$ & $60 \sim 600$ & $600 \sim 3600$ & $>3600$ \\
\hline $\begin{array}{l}\text { Water } \\
\text { repellent } \\
\text { grade }\end{array}$ & Wettable & Slight & Secondary & Serious & Extreme \\
\hline
\end{tabular}

water repellent grade, 20 groups of samples with content of octadecylamine of $0 \%, 0.2 \%, 0.3 \%, 0.5 \%$, and $0.8 \%$ and initial water content of $5 \%, 10 \%, 15 \%$, and $20 \%$ were selected. After sealing for 24 hours, the jack was used to take samples. The soil samples were placed in the consolidometer, and the vertical loads were applied to $50,100,200$, and $400 \mathrm{kPa}$, respectively. The readings were recorded after the predetermined load was stable. After that, pure water was injected to make the pure water $5 \mathrm{~mm}$ higher than the sample. The meter was read every 2 hours, and the stable reading was recorded. After the experiment, the water content after expansion was calculated by drying and weighing.

2.2.5. Direct Shear Tests. According to the test results of water repellent grade of eighteen amine modified expansive soils, $0 \%, 0.2 \%, 0.3 \%, 0.5 \%$, and $0.8 \%$ of the eighteen amine contents correspond to the modified expansive soil with different water repellent grades. The direct shear test was carried out according to the initial dry density $1.56 \mathrm{~g} / \mathrm{cm}^{3}$. According to the standard for soil test methods (GB/T501232019), the unconsolidated undrained direct shear tests of unsaturated water repellent expansive soils with different octadecylamine contents were carried out by using lever type direct shear apparatus (Figure 4).

\section{Test Results and Analysis}

3.1. Water Repellent Grade of Modified Expansive Soil. The water repellent effect diagram is shown in Figure 5, the contact angle diagram is shown in Figure 6, and the measurement results of water repellent grade of expansive soil modified with different octadecylamine contents are listed in Table 2. It can be seen from Figure 5 that the water droplets on the hydrophilic expansive soil had been completely absorbed by the soil, and the water droplets on the surface of the water repellent expansive soil with $0.8 \%$ octadecylamine content still remain full, showing extreme water repellency. The contact angle of hydrophilic expansive soil with $0 \%$ octadecylamine content was $12.114^{\circ}$ and that of water repellent expansive soil with $0.8 \%$ octadecylamine content was $65.441^{\circ}$, respectively. When octadecylamine content was increased from $0 \%$ to $0.8 \%$, the contact angle increases by $54.327^{\circ}$ and the greater the contact angle was, the higher the water repellency of soil was, which indicated that adding octadecylamine to expansive soil could effectively increase the water repellent effect of soil. It can be seen from Table 2 that the water repellent grade of modified expansive soil was wettable without octadecylamine and slight with $0.2 \%$ octadecylamine. Due to the low content of octadecylamine, most of the soil particles were not covered by octadecylamine, and the water repellent grade was still wettable; when octadecylamine content was $0.3 \%$ and $0.5 \%$, the water repellency grade was moderate and severe, and the sample had good water repellency; when octadecylamine content was $0.8 \%$, the water repellent grade of the sample was extreme. It can be shown that the more the octadecylamine content was, the stronger the water repellency of expansive soil was. Because the water repellent grade of modified expansive soil was extreme when octadecylamine content was $0.8 \%$, the modification tests of expansive soil with higher content of octadecylamine are not carried out.

3.2. Free Expansion Rate of Modified Expansive Soil. The test results of free expansion rate of expansive soil modified by different octadecylamine contents are shown in Table 3, and the corresponding free expansion rate change rule is shown in Figure 7. It can be seen that the slope, intercept, and $R^{2}$ of modified expansive soil with different octadecylamine contents was $-27.74,53.39$, and 0.969 , respectively. The more the octadecylamine content, the lower the free expansion rate, and there was a negative correlation between them. When octadecylamine content was $0 \%$, the free expansion rate was $52 \%$. According to the corresponding index, the sample soil was weak expansive soil. When octadecylamine content was $0.2 \%$, the free expansion rate was $49 \%$, which had little change compared with that when octadecylamine content was $0 \%$. When octadecylamine content was $0.3 \%$, the free expansion rate was $45 \%$, showing weak expansion potential. When octadecylamine content was $0.5 \%$, the free expansion rate was $41 \%$, and it would lose its weak expansion potential. When octadecylamine content was $0.8 \%$, the free expansion rate was $30 \%$, which was lower than $40 \%$ of the corresponding index standard. The expansive property of the sample was too small, and it could not be defined as weak expansive soil.

The main reason for the decrease of free expansion rate of expansive soil with the increase of octadecylamine content was that octadecylamine was dissolved and bound to the surface of soil particles when preparing different octadecylamine 


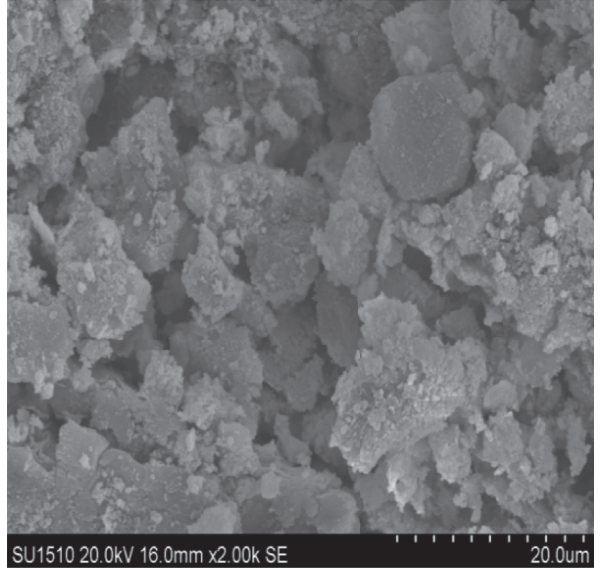

(a)

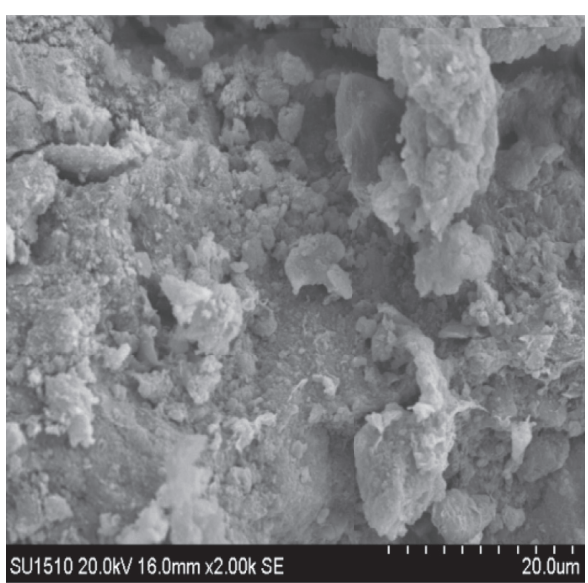

(b)

Figure 2: (a) Soil surface without octadecylamine, 2000x. (b) Soil surface with $0.8 \%$ octadecylamine, $2000 x$.

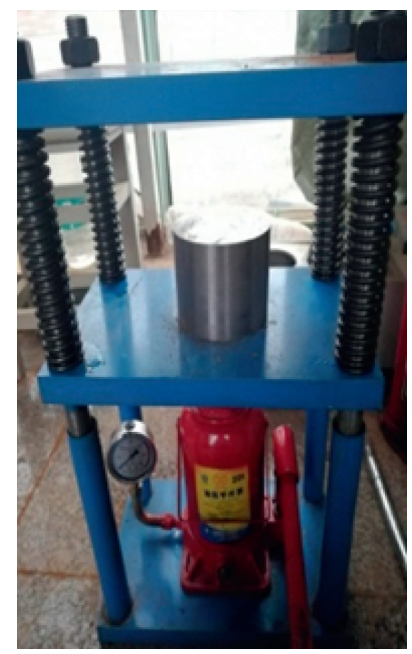

(a)

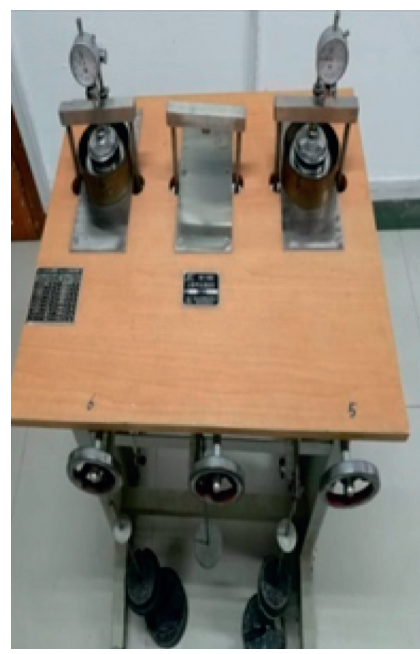

(b)

Figure 3: Hydraulic jack (a). WG-1B triple medium pressure consolidometer (b).

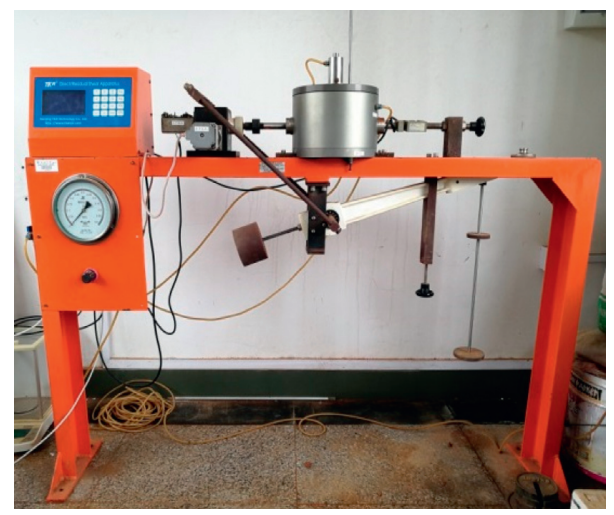

FIGURE 4: Unsaturated direct shear apparatus.

modified expansive soils. In the process of free expansion rate test, the ability of water absorption and expansion of expansive soil was reduced, and the free expansive soil decreases with the increase of octadecylamine content. In this experiment, the free expansion rate of $0.2 \%$ and $0.3 \%$ octadecylamine had little change compared with that of no octadecylamine. When 


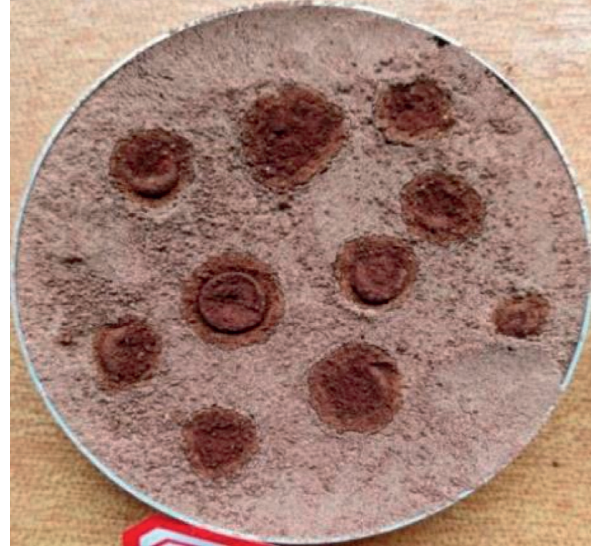

(a)

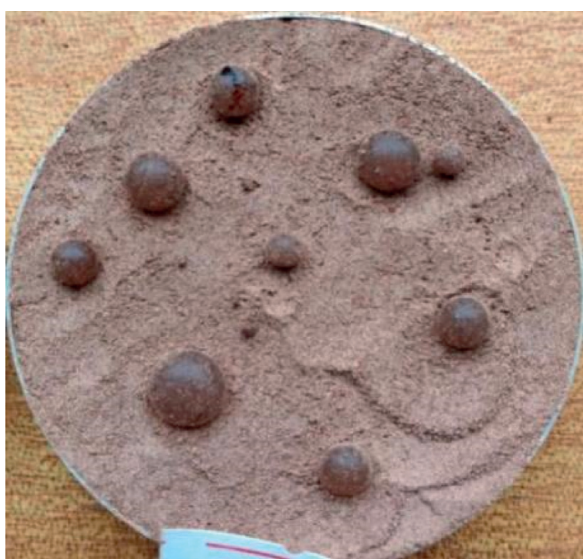

(b)

FIgURE 5: Hydrophilic expansive soil (a). Water repellent expansive soil (b).

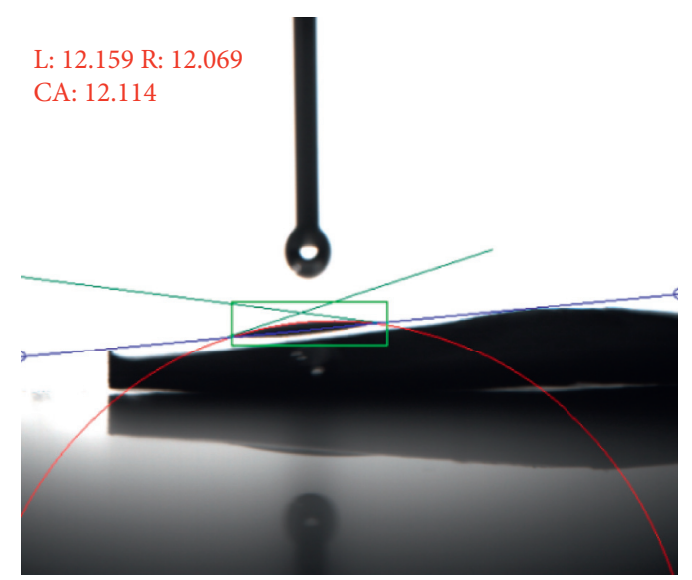

(a)

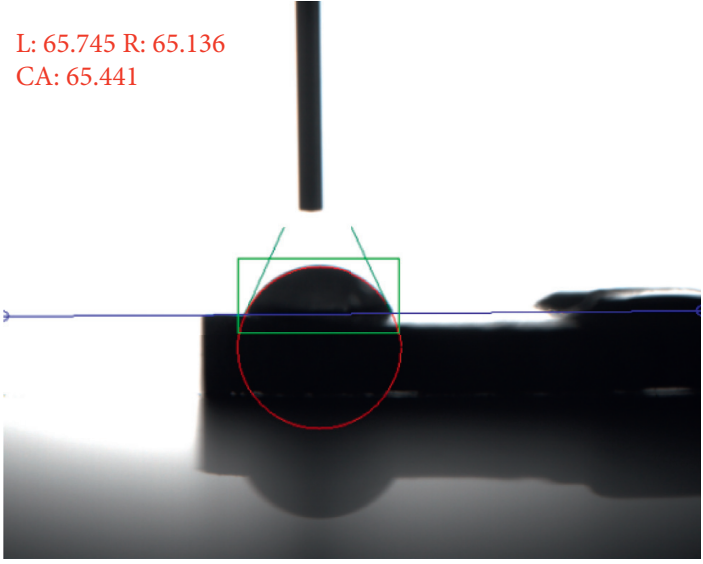

(b)

FIgURE 6: Contact angle of hydrophilic expansive soil (a). Contact angle with hydrophobic expansive soil (b).

TABLE 2: Water repellent grade of modified expansive soil.

\begin{tabular}{lccccc}
\hline Octadecylamine content $(\%)$ & 0 & 0.2 & 0.3 & 0.5 & 0.8 \\
\hline Water repellent grade & Wettable & Slight & Secondary & Serious & Extreme \\
\hline
\end{tabular}

TABle 3: Free swelling rate of modified expansive soil with different octadecylamine contents.

\begin{tabular}{lccc}
\hline Octadecylamine content (\%) & First free expansion rate (\%) & Second free expansion rate (\%) & Average value (\%) \\
\hline 0.0 & 51 & 53 & 52 \\
0.2 & 50 & 48 & 49 \\
0.3 & 46 & 39 & 45 \\
0.5 & 43 & 28 & 41 \\
0.8 & 32 & 30 & 30 \\
\hline
\end{tabular}

octadecylamine content was $0.5 \%$ and $0.8 \%$, the free expansion rate decreased significantly, and the maximum decrease was $42 \%$. It was directly related to the different grades of octadecylamine water repellent expansive soil. The higher the grade of water repellent expansive soil was, the greater the decrease of free expansion rate was. 


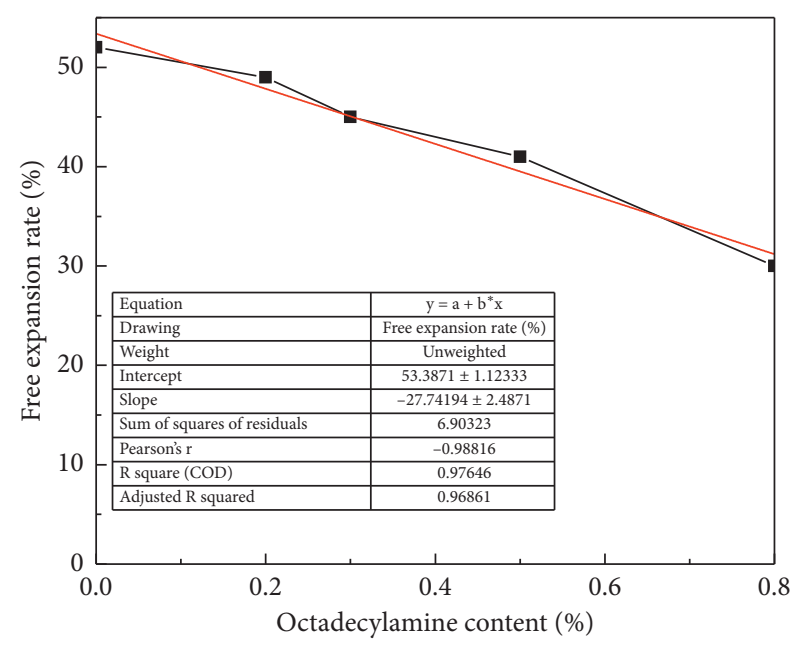

FIGURE 7: Variation of free swelling rate of expansive soil with different octadecylamine contents.

\subsection{Unloaded Expansion Rate of Modified Expansive Soil}

3.3.1. Effect of Octadecylamine and Water Content on Unloaded Expansion. The influence of different octadecylamine contents and sample water contents on the unloaded expansion rate of modified expansive soil is shown in Figure 8. It can be seen from Figure 8(a) that under the same octadecylamine content, the more the water content, the lower the unloaded expansion rate of expansive soil, the larger the area filled with water in the internal pores of the sample, the lower the water absorption capacity, and the less the expansion deformation of the sample. It can be seen from Figure $8(\mathrm{~b})$ that the more octadecylamine content the sample contains, the lower the no-load swelling ratio under the same water content. The more the octadecylamine content was, the larger the area covered by octadecylamine on the surface of expansive soil particles was, the more difficult it was for external water to penetrate into the sample, and the lower the unloaded expansion rate was. When octadecylamine content was increased from $0 \%$ to $0.2 \%$, the unloaded expansion of the sample with $15 \%$ water content decreased from $12.1 \%$ to $9.9 \%$, with a decrease of about $20 \%$. When the octadecylamine content was increased to $0.5 \%$, the rate of unloaded expansion decreased slowly, and the unloaded expansion rate was about 5.6\%. When octadecylamine content was increased to $0.8 \%$, the unloaded expansion rate remained almost unchanged. It can be shown that octadecylamine could reduce the expansibility of expansive soil to a certain extent, but it could not reduce the expansibility indefinitely, and there was a critical range. According to the experimental results in this paper, when octadecylamine content was $0.8 \%$, its water repellent performance reached the extreme, and the unloaded expansion rate could also be effectively reduced.

3.3.2. Influence of Octadecylamine and Water Content on Expansion Time History. Taking the curves of the time-free expansion rate of octadecylamine content of $0 \%, 0.2 \%, 0.5 \%$, and $0.8 \%$, the influence of different octadecylamine contents and water contents on the expansion time course of expansive soil was studied. The results are shown in Figure 9. It can be seen that (1) when the octadecylamine content was the same, the smaller the initial water content of the sample was, the larger the expansion was when the expansion was stable because when the octadecylamine content was the same, the smaller the initial water content was, the more the water infiltrated into the pores of the sample, and the greater the expansion was when the expansion deformation was stable. (2) When octadecylamine was not added, with the passage of time, the amount of expansion of the unloaded expansion rate first increased faster and then stabilized after 4 days. After adding octadecylamine, the expansion time history curve presented an inverted "s" shape: at the initial stage of expansion, the sample absorbed water slowly, and after a certain period of time, the expansion rate increased obviously; after reaching a certain value, the expansion rate slowed down obviously and finally tended to be stable. The presence of octadecylamine would reduce the water infiltration channel to a certain extent and delay the process of water infiltration. The more the octadecylamine content, the more obvious the delay. However, water could still slowly penetrate into the internal pores, but the infiltration time was relatively longer, so the initial expansion rate was smaller, and the curve showed a slow rising type. When the water infiltrated for a certain period of time, the water connectivity in the pores of the sample increased gradually. At this time, the amount of water infiltration increased significantly, and the expansion rate also increased significantly. When the internal pore channels were completely penetrated by water, the expansion rate would be significantly reduced, and the presence of octadecylamine had little effect on water infiltration. (3) When the water content of the sample was the same, the more the octadecylamine content was, the shorter the time for the unloaded expansion rate to reach stability, and the lower the corresponding unloaded expansion rate was. When the water content was $20 \%$ and when octadecylamine content was $0 \%$, the expansion stability time was about $4000 \mathrm{~min}$, and the unloaded expansion rate was $11.18 \%$. When octadecylamine content was $0.8 \%$, the expansion time was about $2000 \mathrm{~min}$, the unloaded expansion rate was $8.16 \%$, and the decrease rate was about $30 \%$.

\subsection{Loaded Expansion Rate of Modified Expansive Soil}

3.4.1. Influence of Initial Water Content on Loaded Expansion Rate. The variation curve of the loaded expansion rate of the sample with different initial water contents is shown in Figure 10. It can be seen that (1) when the octadecylamine content was the same, the more the initial water content was, the lower the charged expansion rate was, which was similar to the test result of unloaded expansion rate; (2) the more the vertical load was, the lower the loaded expansion rate was. When the vertical load was small, octadecylamine content and initial water content had great influence on the loaded expansion rate. With the increase of vertical load, the amplitude gradually decreased, and the load became the main factor affecting the expansion rate. 


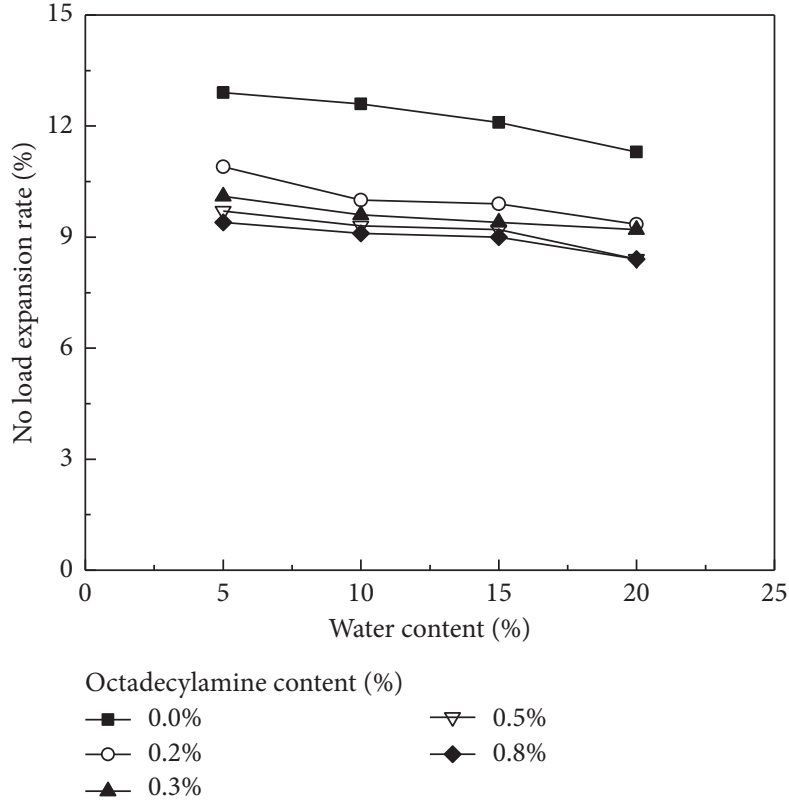

(a)

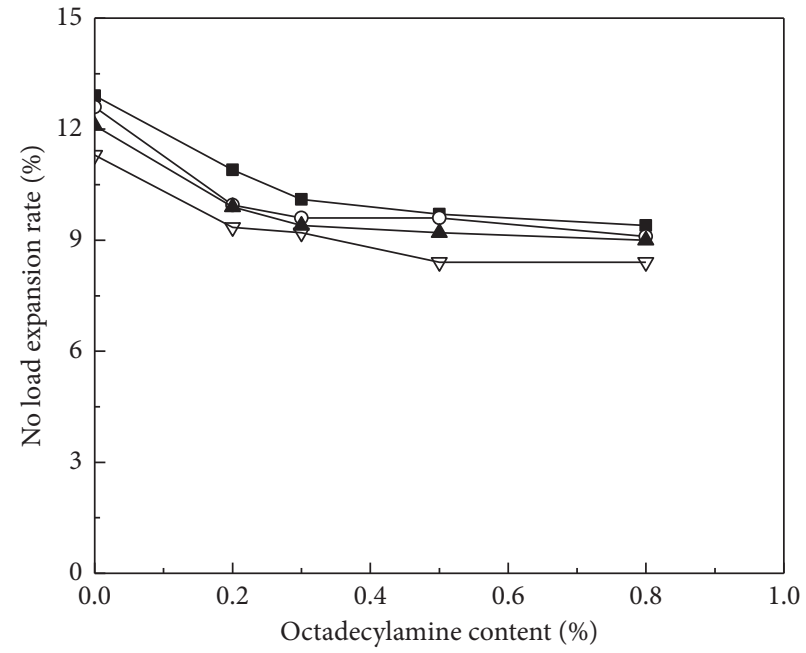

Different moisture content (\%)

$\rightarrow-5 \%$

$\neg 15 \%$

$-0-10 \%$

(b)

FIGURE 8: Relationship between unloaded expansion rate and water content and octadecylamine content. (a) Curve of unloaded expansion with water content. (b) Curve of unloaded expansion with octadecylamine content.
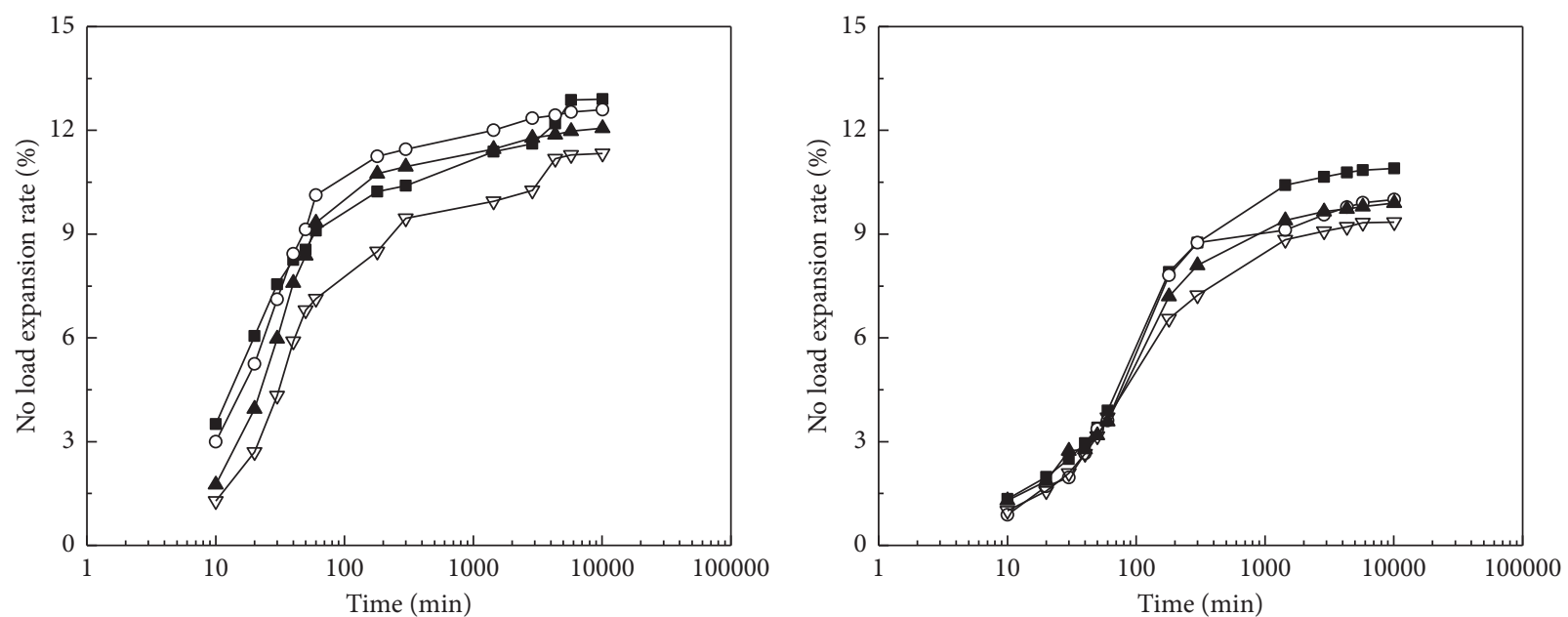

Different moisture content (\%)
$-5 \%$
$-10 \%$
$-15 \%$
$\rightarrow-20 \%$

(a)
Different moisture content (\%)

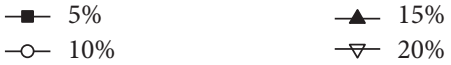

(b)

FIGURE 9: Continued. 


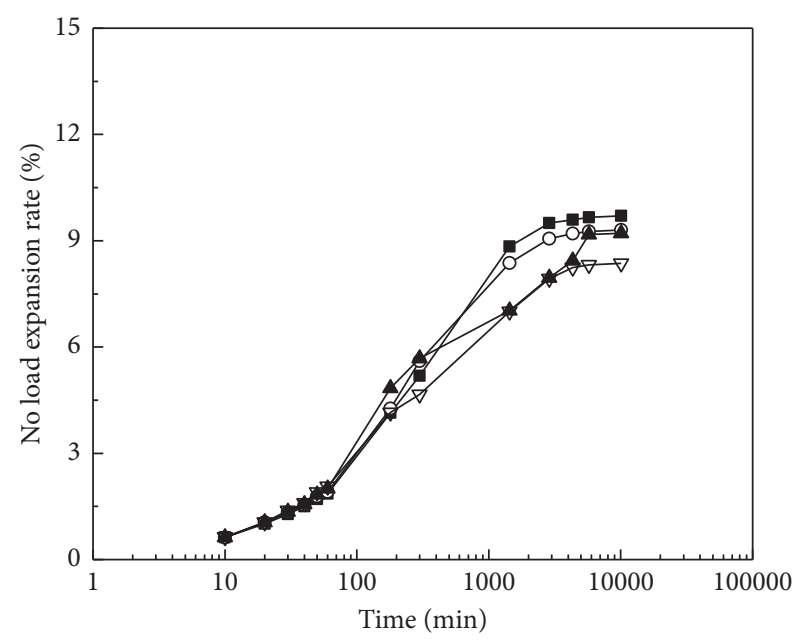

Different moisture content (\%)

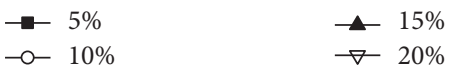

(c)

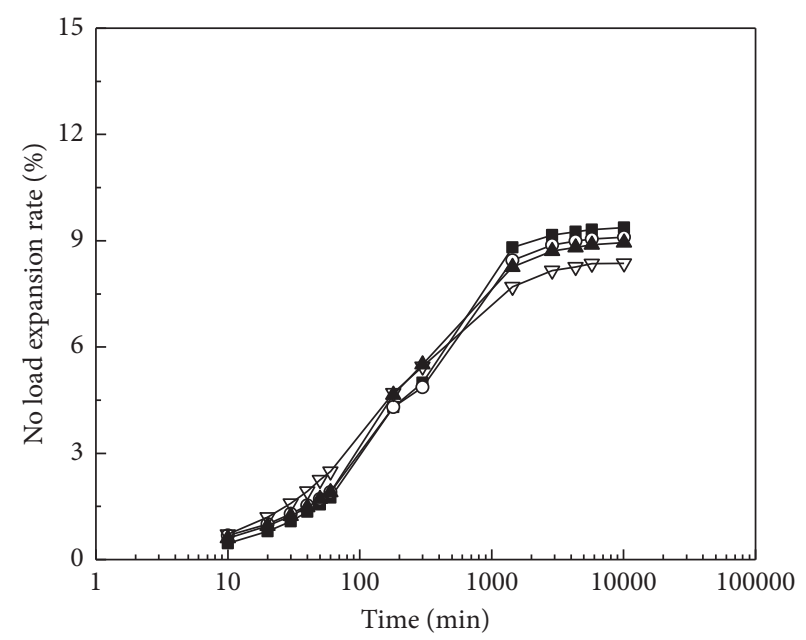

Different moisture content (\%)

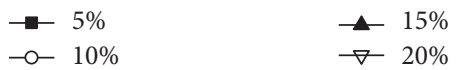

(d)

Figure 9: Time history curves of unloaded expansion for different octadecylamine contents. (a) Octadecylamine content of $0 \%$. (b) Octadecylamine content of $0.2 \%$. (c) Octadecylamine content of $0.5 \%$. (d) Octadecylamine content of $0.8 \%$.

3.4.2. Influence of Octadecylamine Content on Charged Expansion Rate. The relation curve of load expansion rate with different octadecylamine contents is shown in Figure 11. It can be seen that when the vertical load was the same, the more the octadecylamine content was, the lower the load expansion rate of the sample was. When octadecylamine content was $0.8 \%$, the charged expansion rate was the smallest. When the water content of the sample was $20 \%$ and the vertical load was $50 \mathrm{kPa}$, octadecylamine content was decreased from $0 \%$ to $0.8 \%$, and the load expansion rate decreased from $4.89 \%$ to $2.14 \%$, a decrease of about $57 \%$. It can be shown that the presence of octadecylamine could also effectively reduce the swelling property of expansive soil, which was beneficial to engineering.

3.5. Direct Shear Tests. The relationship between horizontal stress and displacement of samples with different octadecylamine contents is shown in Figure 12. It can be seen that (1) the more the vertical load was, the more the maximum horizontal load of hydrophilic expansive soil and water repellent expansive soil were. (2)Under the same vertical load, the more the octadecylamine content was, the stronger the water repellency was and the smaller the maximum horizontal load was. Under the vertical load of $300 \mathrm{kPa}$, the maximum horizontal load of hydrophilic expansive soil was $1300 \mathrm{~N}$. When octadecylamine content was $0.8 \%$, the maximum horizontal load of water repellent expansive soil was $900 \mathrm{~N}$, which was $400 \mathrm{~N}$ less than that of hydrophilic expansive soil. It can be shown that there was a negative correlation between the maximum horizontal load and octadecylamine content.

The relationship between peak shear stress (shear strength) and overlying pressure under different octadecylamine contents is shown in Figure 13. It can be seen that there was a positive correlation between the shear strength and the vertical pressure. The correlation could be described by Mohr-Coulomb strength criterion, and the fitting results are shown in Table 4. It can be seen that under the same vertical load, the more the octadecylamine content was, the lower the shear strength was. When octadecylamine content was higher, the impact on shear strength changed more obviously, and the decline was greater. It can be seen from Table 4 that when the octadecylamine content was $0 \%$, $0.2 \%$, and $0.3 \%, f$ was $44.12^{\circ}, 43.15^{\circ}$, and $39.70^{\circ}$, respectively, and it can be shown that octadecylamine content had little effect on the shear strength of expansive soil. When the octadecylamine content was $0.5 \%$ and $0.8 \%, f$ was $34.459^{\circ}$ and $33.09^{\circ}$, respectively, and the shear strength varied greatly. When octadecylamine content was increased from $0 \%$ to $0.2 \%, 0.3 \%, 0.5 \%$, and $0.8 \%$, the cohesive force of expansive soil decreased gradually, from $132.6 \mathrm{kPa}$ to $109.69 \mathrm{kPa}, 105.6 \mathrm{kPa}, 96.25 \mathrm{kPa}$, and $83.4 \mathrm{kPa}$. It can be seen that the more the water repellent grade of soil samples was, the more the effect of the shear strength was and the lower the shear strength was.

In order to analyze the influence of octadecylamine content and vertical pressure on the shear strength of expansive soil, the envelope diagram of octadecylamine modified expansive soil and octadecylamine content was drawn, as shown in Figure 13.

It can be seen from Figure 14 that (1) when the vertical pressure was $100 \mathrm{kPa}$, the more the octadecylamine content was, the lower the shear strength was. When the vertical pressure was $200 \mathrm{kPa}$, with the increase of octadecylamine content, the shear strength first decreased slowly, then decreased rapidly, and finally tended to be stable. When the vertical pressure was $300 \mathrm{kPa}$, the change law was similar to 

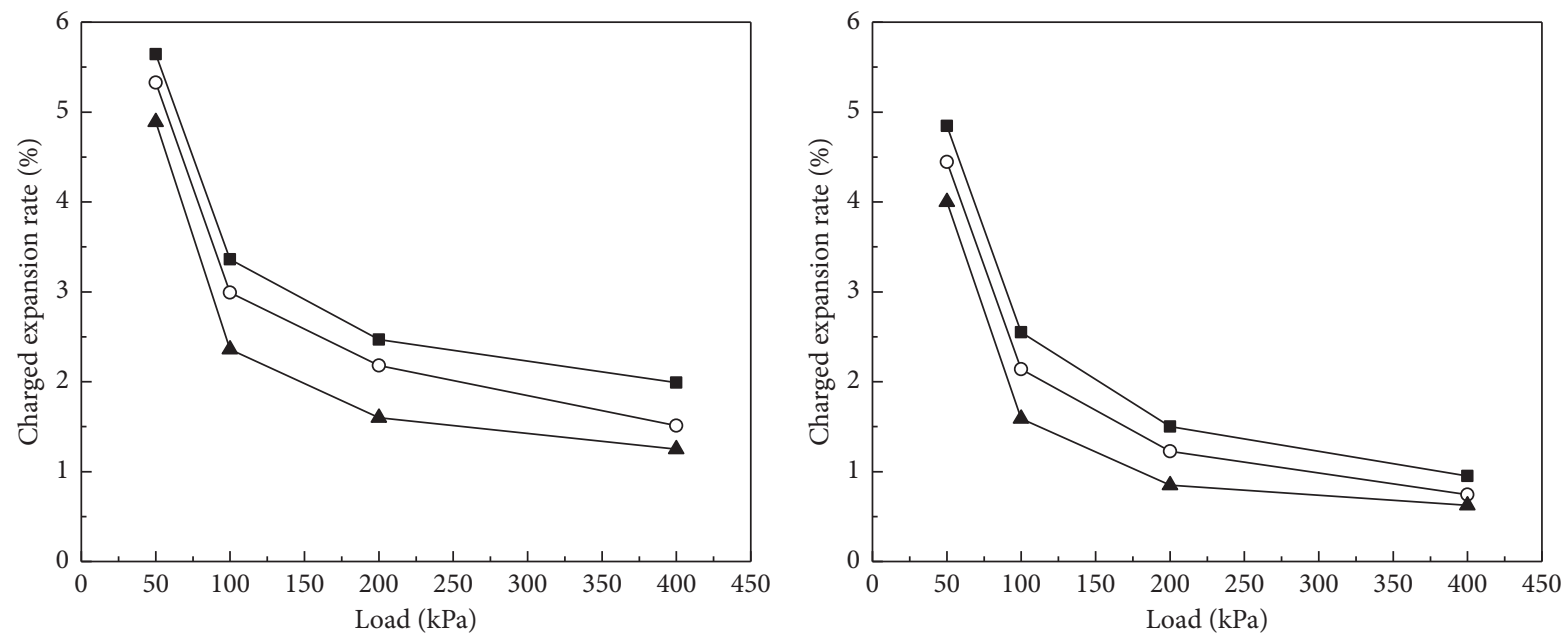

Different moisture content (\%)

Different moisture content (\%)

$\rightarrow-5 \%$

$\rightarrow-5 \%$

$-\circ 10 \%$

$-10 \%$

$-20 \%$

(a)

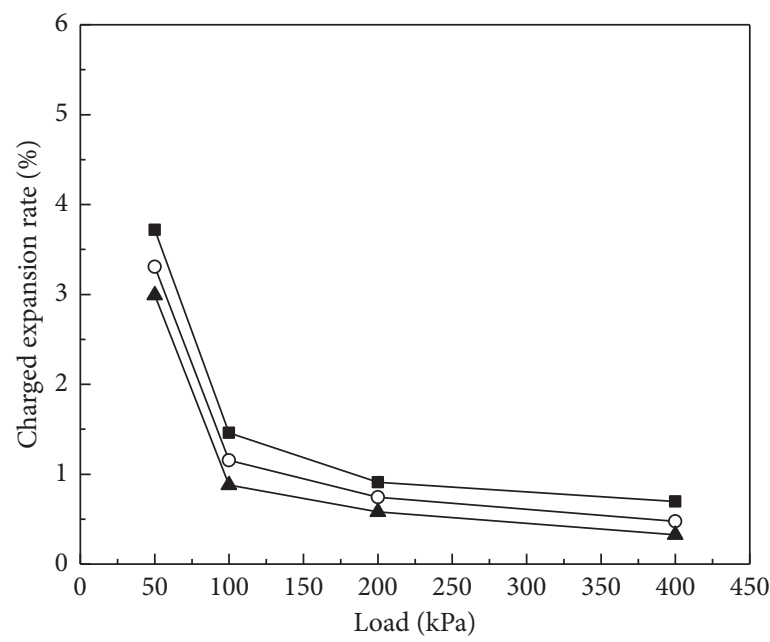

Different moisture content (\%)

$\rightarrow 5 \%$

$-10 \%$

- $20 \%$

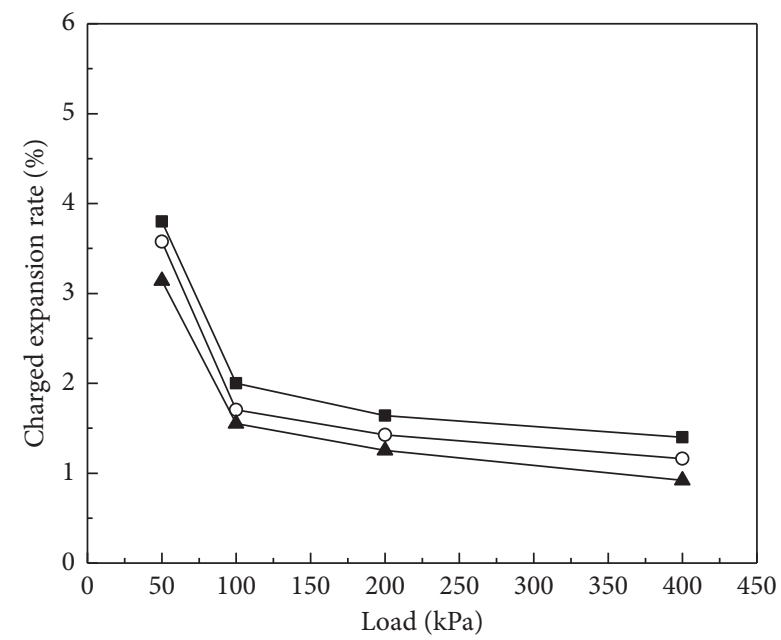

Different moisture content (\%)

$-5 \%$

$-\circ 10 \%$

$-20 \%$

(c)

(d)

FIGURE 10: Relation curve of loaded expansion rate under different water contents. (a) Octadecylamine content of $0 \%$. (b) Octadecylamine content of $0.2 \%$. (c) Octadecylamine content of $0.5 \%$. (d) Octadecylamine content of $0.8 \%$.

that when the vertical pressure was $200 \mathrm{kPa}$. When the vertical pressure was $400 \mathrm{kPa}$, the shear strength decreased with the increase of octadecylamine content. (2) Under different vertical pressures, the shear strength and octadecylamine content were linear. When octadecylamine content was less than $0.3 \%$, the shear strength decreased slowly. When octadecylamine content exceeded $0.3 \%$, the shear strength decreased greatly. When octadecylamine content was $0.5 \%-0.8 \%$, it tended to be stable. In general, with the increase of octadecylamine content, the shear strength first decreased slightly, then decreased greatly, and finally tended to be stable.
The relationship between the octadecylamine content and total internal friction angle is shown in Figure 15. It can be seen that with the increase of octadecylamine content, the internal friction angle decreased, and the decrease range was slightly reduced. The negative exponential equation (1) could be used for fitting.

$$
\varphi=a e^{-b x}+c
$$

where $f$ was the angle of internal friction, $X$ was the octadecylamine content, $a$ was the extent to which the direction was stretched, $b$ was the degree of stretching in the $X$ 

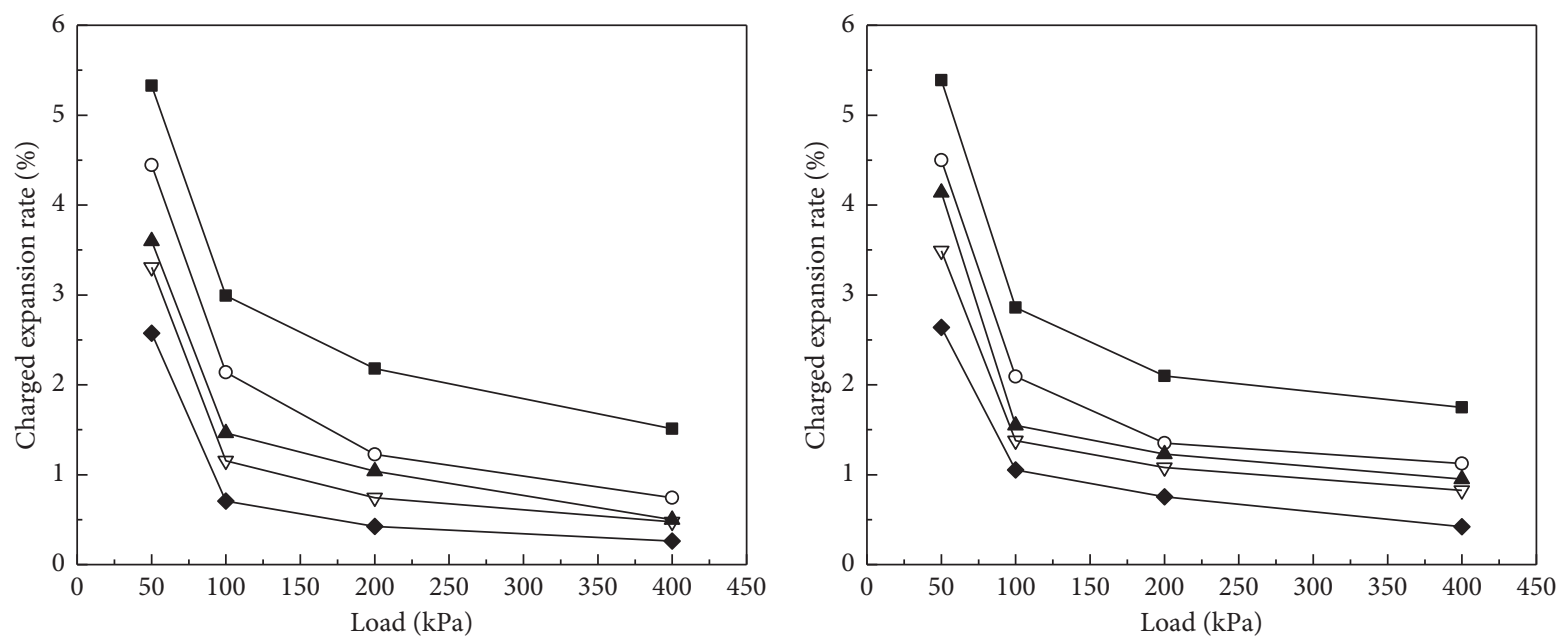

Octadecylamine content (\%)

$\rightarrow 0.0 \%$

$\rightarrow 0.5 \%$

$-0.2 \%$

$\multimap 0.8 \%$

Octadecylamine content (\%)

$-0.0 \%$
$-0-0.2 \%$

$\rightarrow \quad 0.5 \%$

$\longrightarrow 0.2 \%$

$\longrightarrow 0.8 \%$

(a)

(b)

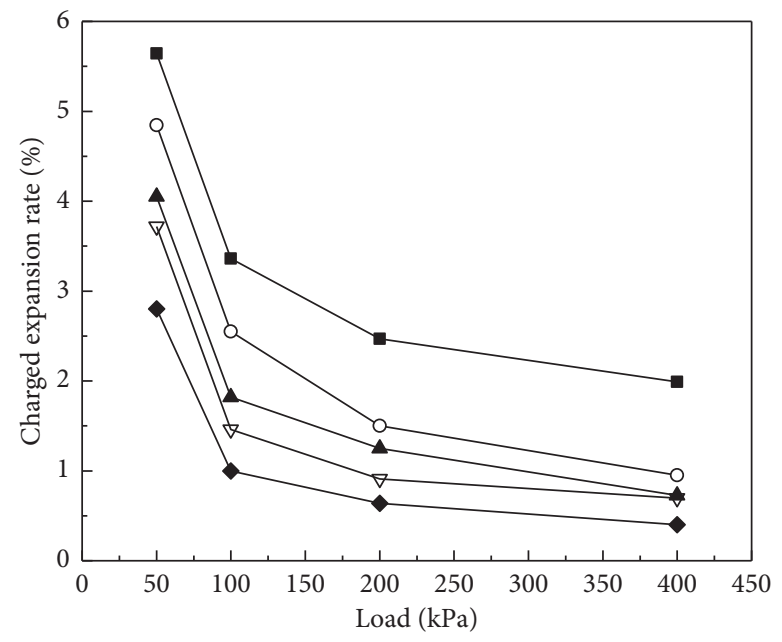

Octadecylamine content (\%)

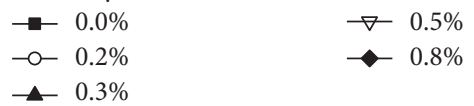

(c)

FigURE 11: Relation between expansion rate and load under different octadecylamine contents. (a) Water content of 5\%. (b) Water content of $10 \%$. (c) Water content of $20 \%$.

direction, and $c$ was the intercept; $a, b$, and $c$ could reflect the relationship between internal friction angle and octadecylamine content to a certain extent. The fitting results are shown in Table 5.

The relationship between octadecylamine content and total cohesion is shown in Figure 16. It can be seen that with the increase of octadecylamine content, the total cohesion presented a linear downward trend, which could be fitted by the first-order (2). On the whole, the shear strength tended to weaken with the increase of octadecylamine content, but the overall decline could still be accepted by the engineering.

$$
c=d x+f
$$

where $c$ was the cohesion, $x$ was the octadecylamine content, $d$ was the slope, and $f$ was the intercept, which could reflect the relationship between cohesion and octadecylamine content to a certain degree. The fitting results are shown in Table 5. 

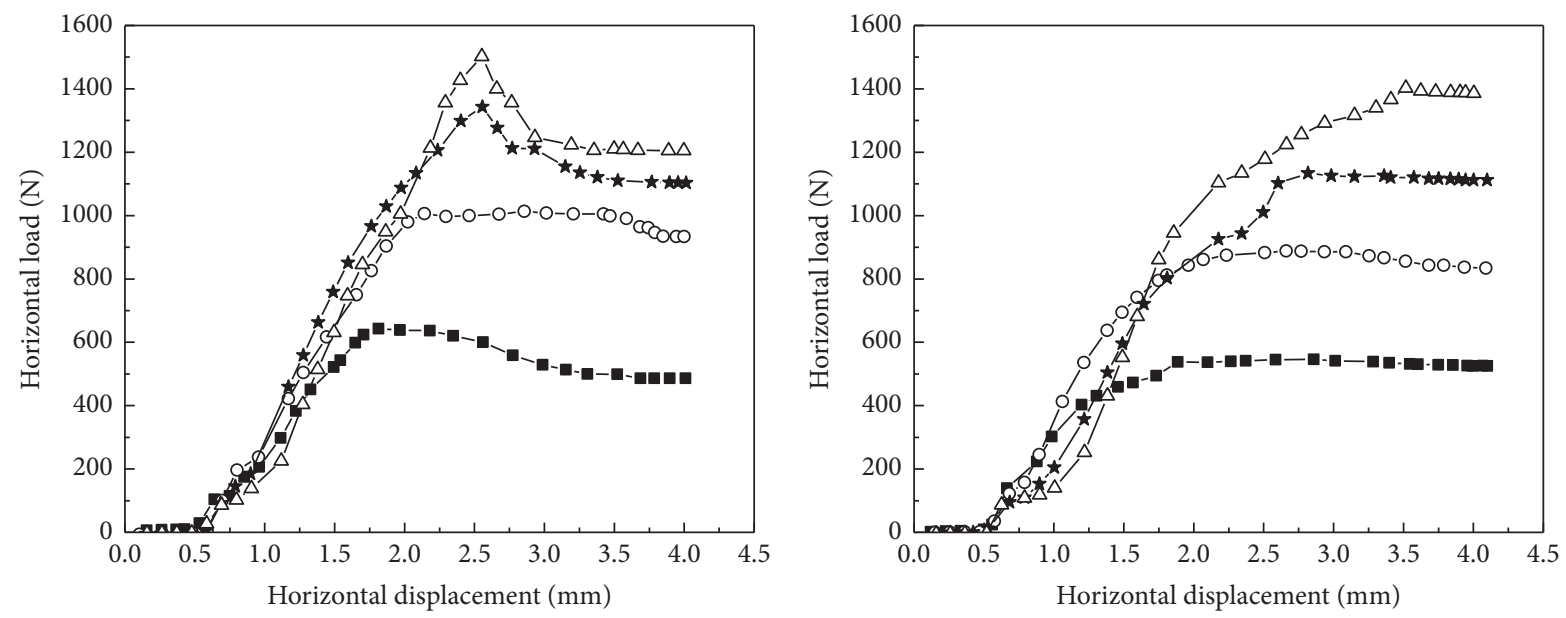

Vertical load $(\mathrm{kPa})$

$\begin{array}{ll}--100 & -\star-300 \\ -0-200 & -\Delta-400\end{array}$

(a)

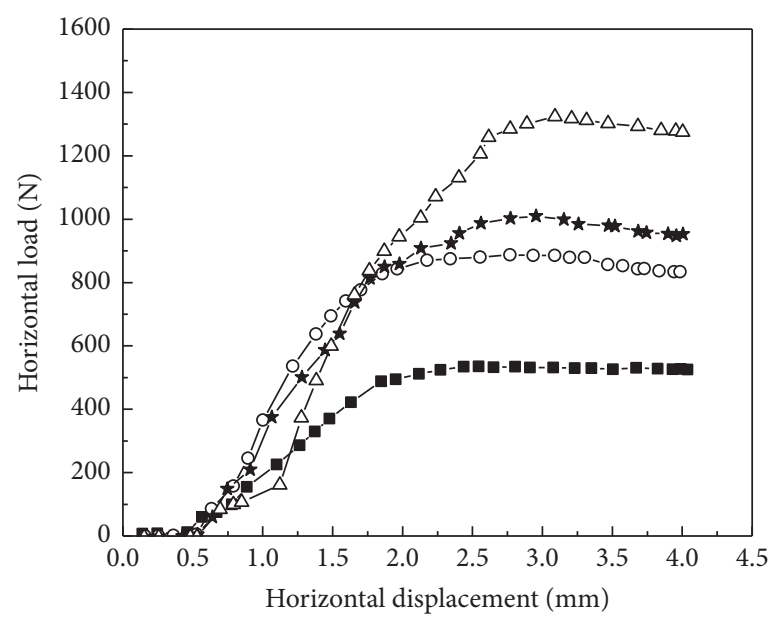

Vertical load (kPa)

$-100$

-o- 200 $-\star-300$

$-\Delta-400$
Vertical load $(\mathrm{kPa})$

$-100$

$-\star-300$

$-\circ-200$

(b)

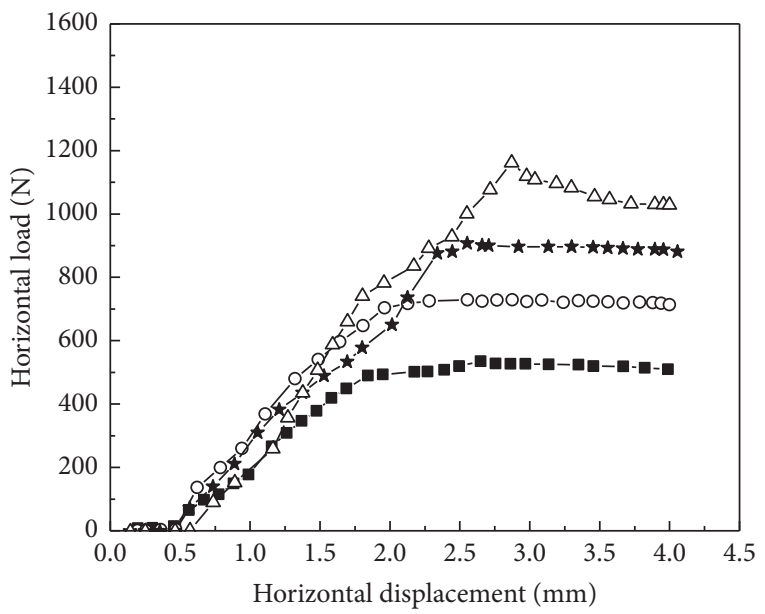

Vertical load (kPa)
$-\square-100$
$-\star-300$
$-0-200$
$-\Delta-400$

(c)

Figure 12: Continued.

(d) 


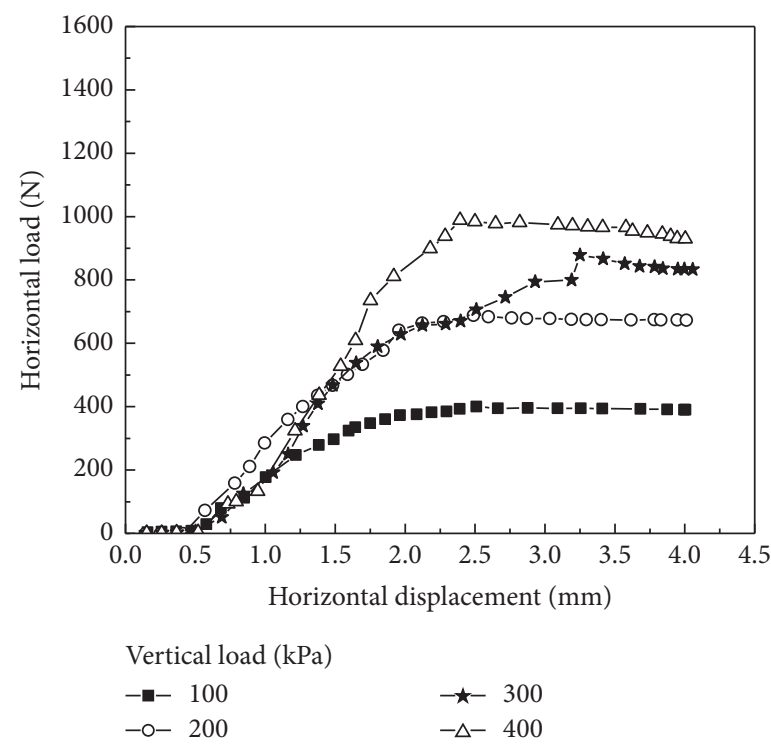

(e)

FigURE 12: Relationship between horizontal load and horizontal displacement of expansive soil with different octadecylamine contents. (a) Octadecylamine content of $0 \%$. (b) Octadecylamine content of $0.2 \%$. (c) Octadecylamine content of $0.3 \%$. (d) Octadecylamine content of $0.5 \%$. (e) Octadecylamine content of $0.8 \%$.

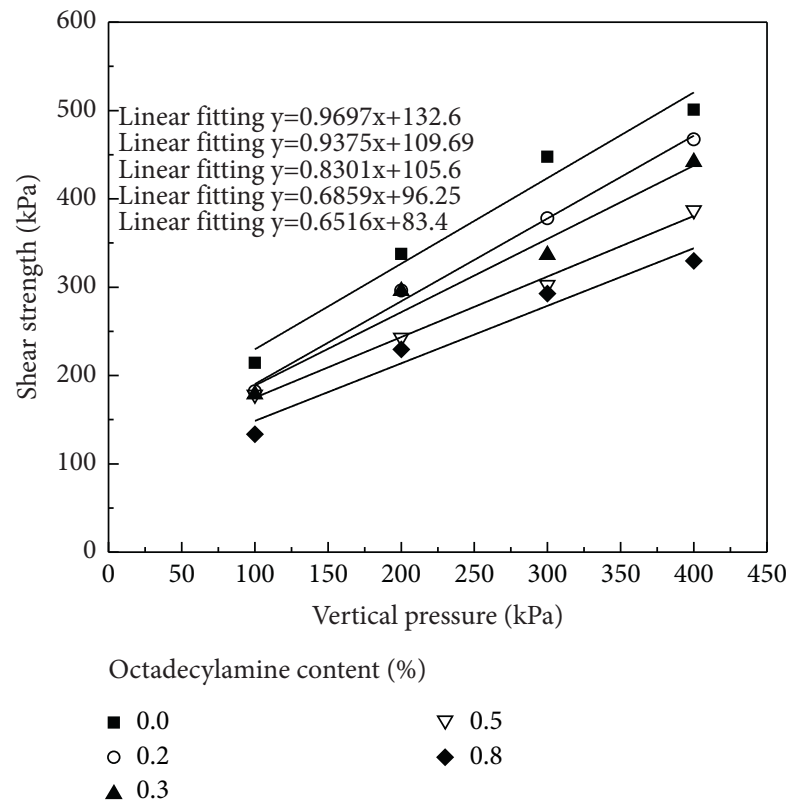

FIGURE 13: Relationship between shear strength and vertical pressure under different octadecylamine contents.

TABLE 4: Fitting results of internal friction angle and cohesion of modified expansive soil with different octadecylamine contents.

\begin{tabular}{lcc}
\hline Octadecylamine content $(\%)$ & $\Phi\left(^{\circ}\right)$ & $\mathrm{C}(\mathrm{kPa})$ \\
\hline 0 & 44.12 & 132.6 \\
0.2 & 43.15 & 109.69 \\
0.3 & 39.70 & 105.6 \\
0.5 & 34.45 & 96.25 \\
0.8 & 33.09 & 83.4 \\
\hline
\end{tabular}




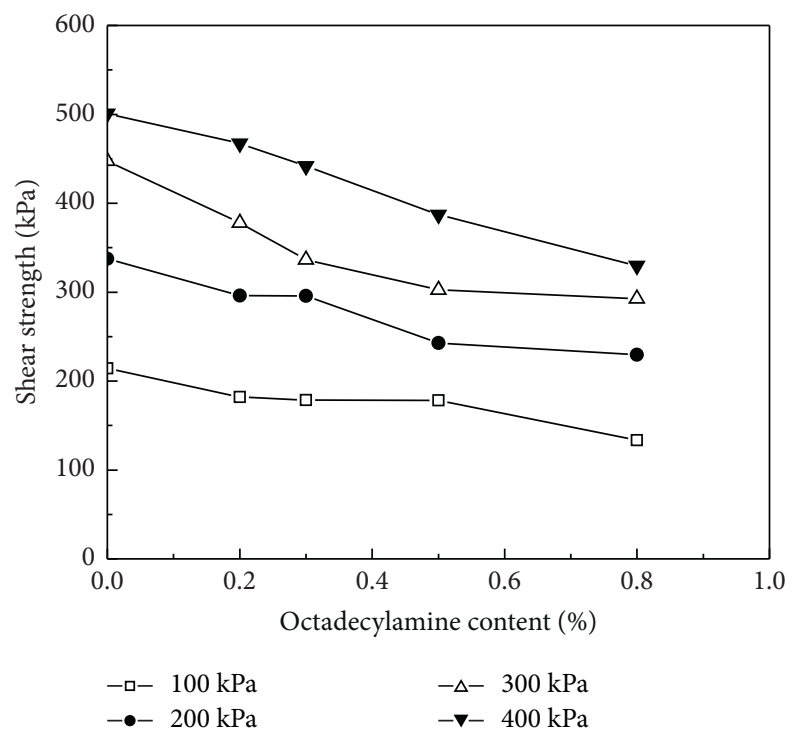

Figure 14: Envelope diagram of shear strength and octadecylamine content under different octadecylamine contents.

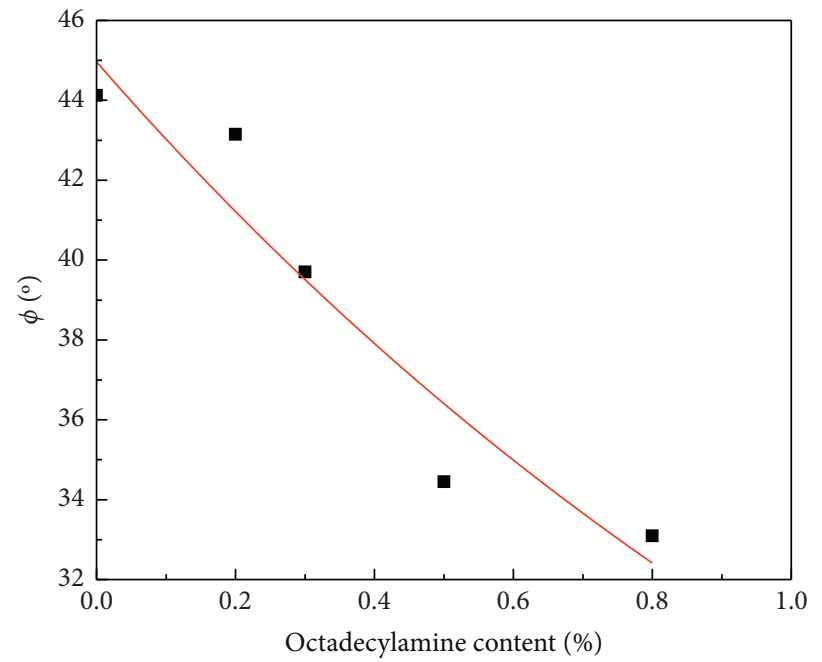

FIGURE 15: Relationship between internal friction angle and octadecylamine content.

TABLE 5: Fitting results.

\begin{tabular}{lcc}
\hline Function & Value & Correlation coefficient \\
\hline Internal friction angle & $a=32$ & 0.999 \\
$\varphi=32 e^{-0.62 x}+12.96$ & $b=0.62$ & 0.996 \\
Cohesion & $c=12.96$ & 0.999 \\
$c=-56.67 x+126.27$ & $d=-57067$ & 0.932 \\
\hline
\end{tabular}

$x$ is octadecylamine content. 


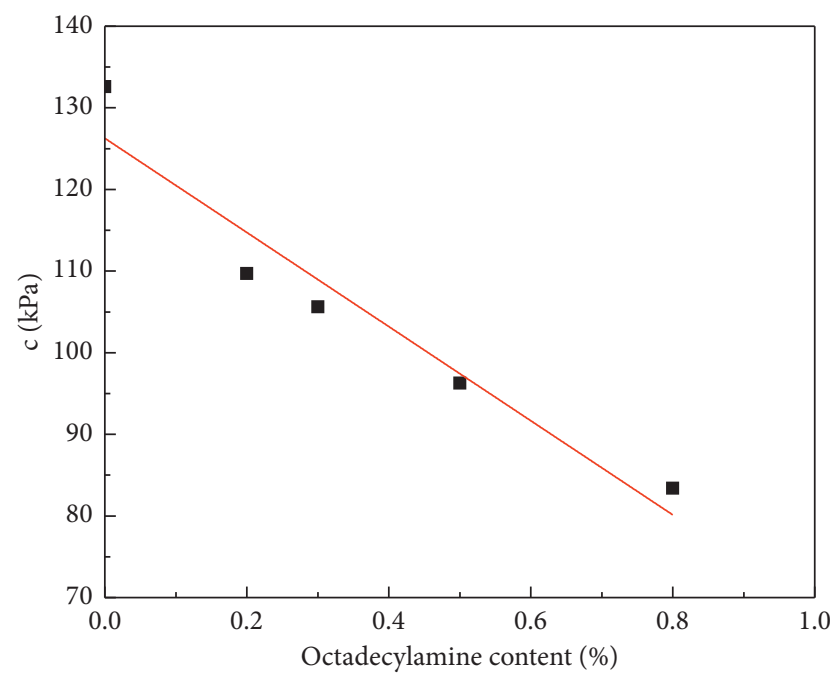

FIGURE 16: Relationship between cohesion and octadecylamine content.

\section{Conclusions}

(1) Water repellent with different octadecylamine contents could reduce the free expansion rate of expansive soil. The more the octadecylamine content is, the lower the free expansion rate is.

(2) The octadecylamine content and initial water content are important factors affecting the expansibility of expansive soil. When octadecylamine content is the same, the more the initial water content is, the lower the unloaded expansion rate and the loaded expansion rate are. The more water content the expansive soil contains, the more obviously the unloaded expansion rate of undisturbed soil decreases. When the water content of the sample is the same, the more octadecylamine content the expansive soil contains, the lower the unloaded expansion rate is and the more it tends to be stable. The existence of octadecylamine could effectively reduce the expansibility of expansive soil.

(3) Under the same octadecylamine content, the more the vertical load is, the lower the loaded expansion rate is. When the vertical load was small, octadecylamine content and initial water content had great influence on the loaded expansion rate. When the vertical load was large, the load was an important factor affecting the expansibility of expansive soil. When the vertical load was constant, the more the octadecylamine content is, the lower the loaded expansion rate is.

(4) The existence of octadecylamine can effectively inhibit the swelling characteristics of expansive soil. When the octadecylamine content is greater than or equal to $0.8 \%$, the water repellent grade is extreme, which can inhibit the water swelling of expansive soil to a great extent, and the water repellent effect is good, which can provide a reference for solving the related problems in the expansive soil area. The more the vertical pressure, the more the shear strength of hydrophilic expansive soil and water repellent expansive soil.

(5) Under the same vertical pressure, the more the octadecylamine content is, the lower the shear strength is, and when octadecylamine content is increased, the influence of the shear strength was greater. The shear strength is negatively correlated with the water repellent grade. It has been shown that the influence of the shear strength is greater with the increase of the water repellent grade. Under different vertical pressures, the shear strength has a linear relationship with octadecylamine content, which conformed to the Mohr-Coulomb shear strength criterion.

\section{Data Availability}

The data used to support the findings of this study are included within the article.

\section{Disclosure}

All opinions, findings, and conclusions in this work represent the views of the authors only.

\section{Conflicts of Interest}

The authors declare that they have no conflicts of interest.

\section{Acknowledgments}

This study was supported by Project (51869013) of the National Natural Science Foundation of China, Project (SLK2021A05) of Open Research Fund of Key Laboratory of Hydraulic and Waterway Engineering of the Ministry of Education, Project (YK321013) of Open Research Fund of Key Laboratory of Failure Mechanism and Safety Control Techniques of Earth-Rock Dam of the Ministry of Water Resources, and Project (YC2020-094) of Innovation Fund of Nanchang Hangkong University for Graduate Students.

\section{References}

[1] W. Yang, "Significance of seepage prevention of water conservancy project channel and its technical measures," Henan water conservancy and south to North Water Diversion, vol. 4, pp. 18-19, 2015.

[2] D. G. Toll, "Briefing: r," Proceedings of the Institution of Civil Engineers - Geotechnical Engineering, vol. 149, no. 4, pp. 211216, 2001.

[3] L. Chengyan, X. Hewei, L. Ya et al., "Discussion on slope piping phenomenon and slope safety," Value Engineering, vol. 37, no. 25 , pp. 107-109, 2018.

[4] C. Liang, "Investigation and evaluation method of ground deformation geological disaster," Science and technology and enterprise, vol. 15, p. 115, 2011.

[5] F. Guangliang, B. Chen, Q. Jiang et al., "Excavation-induced microseismicity and rockburst occurrence: similarities and differences between deep parallel tunnels with alternating soft-hard strata," Journal of Central South University, vol. 28, pp. 582-594, 2021. 
[6] J. Chen, L. Kong, Y. Zhao et al., "Analysis of influence factors of suction and deformation of unsaturated soil under evaporation," Geotechnical mechanics, vol. 28, no. 9, pp. 1967-1773, 2007.

[7] F. Guangliang, X. Feng, B. Chen et al., "A microseismic method for dynamic warning of rockburst development processes in tunnels," Rock Mechanics and Rock Engineering, vol. 48, no. 5, pp. 2061-2076, 2015.

[8] Y. Zhang, C. Guo, Y. Qu et al., "Discovery of expansive diatomite in Tengchong, Yunnan Province and its engineering geological significance," Acta Geologica Sinica, vol. 20, no. 2, pp. 266-275, 2012.

[9] S. Li and H. Chen, "The effect of quicklime on reducing the expansive soil disaster -- Taking Shandong (an) - lai (Wu) first class highway as an example," Journal of geological disasters of China, no. 1, pp. 67-74, 1992.

[10] S. Fang and H. Yao, "Effect of $\mathrm{K}+$ on swelling rate of expansive soil," Journal of Anhui Jianzhu University, vol. 27, pp. 23-28, 2019.

[11] W. E. Ring, "Shrink-swell Potentials of Soil," Highway Research Record No. 119, pp. 17-21, National Academy of SciencesNational Council publication, Washington, DC, USA, 1966.

[12] U. Koyluoglu, Soil Mechanics for Unsaturated Soils: D. G. Fredlund \& H. Rahardjo, John Wiley \& Sons, Hoboken, NJ, USA, pp. 449-450, 1993.

[13] L. Gao, S. Ding, H. Du et al., "Research progress of modified treatment methods of expansive land in China," Exploration and mining engineering in the west, vol. 7, pp. 41-44, 2006.

[14] H. Li, X. Yu, L. Lu et al., "Experimental study on lime modification of expansive soil in highway engineering," Journal of Shandong University of Technology, vol. 1, pp. 92-96, 2002.

[15] Z. Qiu and M. Yang, "Experimental study on mechanical properties of lime modified expansive soil," Subgrade engineering, vol. 3, pp. 32-35, 2000.

[16] W. Lee, M.-K. Jin, W.-C. Yoo, and J.-K. Lee, "Nanostructuring of a polymeric substrate with well-defined nanometer-scale topography and tailored surface wettability," Langmuir, vol. 20, no. 18, pp. 7665-7669, 2004.

[17] J. Zeng, C. Wen, J. Bao et al., "Laboratory triaxial test of enzyme modified expansive soil," Chinese scientific paper, vol. 12, no. 6, pp. 660-665, 2017.

[18] M. M. Roper, "The isolation and characterisation of bacteria with the potential to degrade waxes that cause water repellency in sandy soils," Soil Research, vol. 42, no. 4, pp. 427-434, 2004.

[19] C. Franco, M. Tate, and J. Oades, "Studies on non-wetting sands .1. The role of intrinsic particulate organic-matter in the development of water-repellency in non-wetting sands," Soil Research, vol. 33, no. 2, pp. 253-263, 1995.

[20] S. Qu and Y. Tang, "Experimental study on chemical improvement of expansive soil," Jiangxi building materials, vol. 22, pp. 5-6, 2017.

[21] J. Wu, X. Zhou, L. Hui et al., "Determination and variation of soil water repellency under different water repellents," Journal of agricultural engineering, vol. 34, no. 17, pp. 109-115, 2018.

[22] J. Wu and L. Hui, "Determination of shear strength of unsaturated soil under the action of water repellent and its changing law," Journal of agricultural engineering, vol. 35, no. 6, pp. 123-129, 2019.

[23] M. Malekzadeh and H. Bilsel, "Use of posidonia oceanica ash in stabilization of expansive soils," Marine Georesources \& Geotechnology, vol. 32, no. 2, 2014.

[24] J. Khazaei and H. Moayedi, "Soft expansive soil improvement by eco-friendly waste and quick lime," Arabian Journal for Science and Engineering, vol. 44, no. 10, 2019.
[25] C. Moghal and A.-M. Basha, "Effect of polypropylene fibre reinforcement on the consolidation, swell and shrinkage behaviour of lime-blended expansive soil," International Journal of Geotechnical Engineering, vol. 12, no. 5, 2018.

[26] R. A. Blayi, A. F. H. Sherwani, H. H. Ibrahim et al., "Strength Improvement of Expansive Soil by Utilizing Waste Glass Powder," Case Studies in Construction Materials, vol. 13, 2020.

[27] P. Wang, X. Song, H. Xu, and W. Zhou, "Experiment on basic properties of cement modified expansive soil," Progress of water conservancy and hydropower technology, vol. 41, no. 3, pp. 56-60, 2021.

[28] Yu Meng, J. Zhang, Y. Zhou, and F. Sun, "Experimental study on modified expansive soil by micp technology," Journal of Yangtze River academy of Sciences, vol. 38, no. 5, pp. 103-108+122, 2021.

[29] H. Miao, Experimental Study on Chemical Modification and Mechanical Properties of Expansive Soil, Dalian University of technology, Dalian, China, 2007.

[30] Q. Wang, Experimental Study on Physical and Mechanical Properties and Chemical Modification of Expansive Soil in Ankang Area, Chang'an University, Xi'an, China, 2011.

[31] M. Wang, S. Qin, L. Jian et al., "Experimental study on unsaturated strength of lime modified expansive soil in Hefei," Journal of rock mechanics and engineering, vol. 33, no. S2, pp. 4233-4238, 2014.

[32] Yu Jin, H. Wang, C. Zheng et al., "Surface adsorption test and water absorption verification of lime mixed expansive soil," Geotechnical mechanics, vol. 33, no. 1, pp. 73-77, 2012.

[33] M. Liu, J. Song, J. Liu et al., "Experimental study on construction uniformity of cement modified expansive soil," Journal of geotechnical engineering, vol. 39, no. S1, pp. 59-63, 2017.

[34] W. Zou, P. Xie, Q. Ma et al., "Experimental study on expansive soil modified by waste tire rubber particles," Journal of Sichuan University (Engineering Science Edition), vol. 43, no. 3, pp. 44-48, 2011.

[35] X. Zhang, S. Sun, W. Yongyao et al., "Laboratory test study of expansive soil modified by adding green sand," Geotechnical mechanics, vol. 33, no. S2, pp. 209-212, 2012.

[36] X. Zhuang and X. Yu, "Experimental study on strength characteristics of lime basalt fiber modified expansive soil," Journal of Civil Engineering, vol. 48, no. S1, pp. 116-120, 2015.

[37] S. Sun, J. Tang, Q. Zheng et al., "Experimental study on improvement of expansive soil mixed with blast furnace slag," Geotechnical mechanics, vol. 33, no. 7, pp. 1940-1944, 2012.

[38] T. H. Wu, C. M. Kokesh, and B. R. Trenner, "Use of live poles for stabilization of a shallow slope failure," Journal of Geotechnical and GeoEnvironmental Engineering, vol. 140, no. 10, pp. 1-13, 2014.

[39] H. Yao, S. Zheng, and S. Chen, "Stability analysis of expansive soil slope considering crack and rainwater infiltration," Chinese Journal of Geotechnical Engineering, vol. 23, no. 5, pp. 606-609, 2001.

[40] Ma Jia, "Experimental study on fracture evolution process of fractured soil," Geotechnical mechanics, vol. 28, no. 10, pp. 2203-2208, 2007.

[41] J. Wu, L. Hui, J. Liu et al., "Study on water repellency and infiltration properties of loam modified by octadecylamine," Acta Agriculturae engi neering Sinica, vol. 35, no. 13, pp. 122-128, 2019. 